*Pós Doutor pela Max-PlanckInstitut für ausländisches und internationales Privatrecht, (MPIPRIV). Doutorando em Direito pela Albert-LudwigsUniversitaet Freiburg (UNI FREIBURG). Doutor em Direito pela Universidade de São Paulo (USP). Mestre em Direito pela Pontifícia Universidade Católica de São Paulo (PUCSP). Bacharel em Direito pela Universidade de São Paulo (USP). Email: assiszanini@gmail.com

\section{A Contratação Na Sociedade Massificada E As Condições Gerais De Contratação No Direito Alemão}

\author{
The Contracts In Mass Society And The General \\ Conditions Of The Contracts In German LaW
}

\section{Leonardo Estevam de Assis Zanini*}

Como citar: ZANINI, Leonardo Estevam de Assis. A contratação na sociedade massificada e as condições gerais de contratação no direito alemão. Scientia Iuris, Londrina, v. 24, n. 2, p. 117-133, jul. 2020. DOI: 0.5433/2178-8189.2020v24p117. ISSN: 21788189.

Resumo: O presente artigo analisa o tratamento dado pelo direito alemão às condições gerais de contratação, assunto bastante relevante para o sistema contratual existente na sociedade massificada. A utilização de contratos que são acompanhados de condições gerais de contratação é atualmente muito comum. $\mathrm{O}$ texto analisa a maneira como o Código Civil alemão permitiu a inclusão das condições gerais de contratação nos negócios jurídicos, bem como as situações em que o juiz está autorizado a fazer um controle do seu conteúdo. Também estuda o campo de atuação e a forma como devem ser interpretadas as condições gerais de contratação. Por fim, ressalta que o sistema alemão regula a matéria desde 1976, apresentando legislação muito mais estruturada que o ordenamento jurídico brasileiro, o que permite um controle mais geral e abstrato da temática, bem como garante maior segurança jurídica.

Palavras-chave: Sociedade massificada. Direito civil. Direito alemão. Condições gerais de contratação. Proteção do consumidor.

Abstract: This article examines the way in which German law interprets the general conditions of contracts, a subject that is very 
relevant to the contractual system of mass society. Currently, it is very common to use contracts accompanied by some general conditions. Therefore, this paper examines how the German Civil Code has permitted the inclusion of general conditions of contracts in legal transactions, as well as in situations in which the judge is authorized to check the content of the general conditions of the contract. This paper also studies its field of action and the way in which the general conditions of the contracts are to be interpreted. Finally, this research emphasizes that the German system has regulated the matter since 1976 and presents a much more structured legislation than in the Brazilian legal system, which has allowed the Germans a more general and more abstract control of the matter, ensuring greater legal certainty.

Keywords: Mass society. Civil law. German law. General conditions of the Contracts. Consumer Protection. 


\section{INTRODUÇÃO}

A sociedade de massas produziu alterações bastante sensíveis na dinâmica do direito contratual, não se fazendo mais adequado o modelo liberal clássico do contrato (LÔBO, 2011, p. 121). A aceleração do ritmo das negociações e a desigualdade, cada vez mais significativa, entre as partes contratantes, proporcionaram o surgimento e o desenvolvimento de contratos padronizados. $\mathrm{Na}$ atualidade os contratos padronizados, que muitas vezes contam com condições gerais de contratação, são instrumentos negociais imprescindíveis e onipresentes, situação que não é diferente na seara negocial alemã e brasileira (ZANINI, 2017, p. 75-76). Sua utilização se explica pelo desejo das empresas de previamente redigirem seus contratos, afastando a aplicação de regras contratuais livremente discutidas pelas partes, tudo em proveito de regras massificadas impostas de forma unilateral (FÖRSCHLER, 2018, p. 79-80).

Como essa técnica contratual apresenta vantagens e desvantagens para os contraentes, é certo que hodiernamente a regulamentação relativa às condições gerais de contratação ocupa um lugar importante na legislação atinente à teoria geral dos contratos, visto que essas cláusulas interferem na liberdade de organização do conteúdo do contrato (BROX; WALKER, 2019, p. 39).

Desse modo, o texto em questão objetiva apresentar os fundamentos da legislação alemã sobre as condições gerais de contratação. Trata-se de um estudo no qual a metodologia utilizada é descritiva e dedutiva, baseada fundamentalmente na investigação bibliográfica, jurisprudencial e legislativa. Ao mesmo tempo em que informa, o estudo panorâmico da matéria também busca instigar o leitor a procurar soluções no direito alemão para problemas existentes no Brasil. Igualmente, são feitos apontamentos específicos sobre eventuais diferenças existentes entre o direito alemão e brasileiro, que certamente permitirão uma melhor compreensão do papel socioeconômico desse instituto. Para tanto, serão abordados particularmente os seguintes temas: a) a área de atuação das condições gerais de contratação; b) a sua incorporação nos contratos e; c) o controle de seu conteúdo.

\section{O SIGNIFICADO PRÁTICO DAS CONDIÇÕES GERAIS DE CONTRATAÇÃO}

A celebração de um contrato certamente não depende de qual das partes tenha formulado os seus termos, bem como os tenha fixado por escrito. Em realidade, o fator decisivo em uma contratação é que as partes concordem exatamente com as condições estabelecidas.

Nessa linha, a legislação prevê a existência de muitas normas como direito dispositivo. Toma-se como ponto de partida a concepção tradicional de que a negociação de um contrato não depende apenas de uma das partes, mas sim de concessões feitas por ambas as partes, de maneira que uma parte contratual só estaria disposta a renunciar a direitos concedidos pela lei se lhe forem oferecidas outras vantagens como compensação.

Todavia, como regra, não há discussão sobre as cláusulas contratuais pré-formuladas quando uma 
das partes faz uso das condições gerais para alterar ou complementar um determinado tipo de contrato (SCHLECHTRIEM, 2003, p. 43). De fato, as condições gerais de contratação contêm aditamentos e alterações das disposições legais. Essas cláusulas facilitam, sem dúvida, a vida do utilizador (predisponente), trazendo vantagens em termos de custos, mas também repercutem na esfera do cliente, pois proporcionam preços mais favoráveis e atendimento mais eficiente (BÄHR, 2013, p. 119-120). Isso ocorre, sobretudo, em relação a empresas que concluem transações comerciais repetidas com um grande número de clientes, as quais apresentam direitos e deveres semelhantes, fazendo sentido registrar os termos gerais da contratação por escrito e, em seguida, apenas fazer referência a eles ao concluir a transação individual (LÔBO, 2011, p. 122).

Assim sendo, as condições gerais de contratação (Allgemeiner Geschäftsbedingungen - ABG) desempenham um importante papel na prática contratual (KLUNZINGER, 2013, p. 111). Atualmente, elas são utilizadas por uma ampla gama de atividades empresariais, como bancos, companhias de seguros, planos de saúde, empresas de telefonia, fabricantes de bens e prestadores de serviços (FÜHRICH, 2014, p. 148). Elas oferecem aos contratantes, particularmente aos fornecedores, a oportunidade de padronizar seus serviços, estruturar uniformemente seus negócios, reduzir os custos das transações, bem como possibilitam o cálculo dos riscos em caso de inadimplemento (BROX; WALKER, 2019, p. 42).

Por outro lado, apesar de suas inegáveis vantagens, o uso das condições gerais também apresenta riscos (LOOSCHELDERS, 2017, p. 121). Muitas vezes aquele que utiliza as condições gerais de contratação tem que lidar com clientes inexperientes, que não conseguem ler as "cláusulas escritas em letras pequenas" (Kleingedrucktes) e acabam assinando mais ou menos cegamente os formulários contratuais que lhes são apresentados (BOECKEN, 2019, p. 178). Com isso, existe o risco dos utilizadores das condições gerais de contratação estabelecerem a seu favor, de forma unilateral, os termos e condições dos contratos por eles celebrados, obtendo então vantagens injustificadas por abusarem da liberdade contratual concedida por lei (FÖRSCHLER, 2018, p. 80). É dizer: diante da hipossuficiência de uma das partes e da força econômica da outra, a liberdade contratual permite que a parte mais forte desequilibre a relação contratual a seu favor, o que se agrava muito pelas particularidades das condições gerais de contratação ${ }^{1}$.

Por conseguinte, diante do uso constante das condições gerais de contratação, realidade que não pode ser ignorada e não pode ser evitada, o legislador alemão procurou fazer um controle dessas cláusulas para evitar a submissão da parte mais fraca à vontade da parte economicamente mais forte, mantendo, assim, o equilíbrio contratual e a justiça (BOECKEN, 2019, p. 179).

\section{FONTES DA REGULAMENTAÇÃO ATUAL}

O legislador alemão se ocupou do problema das condições gerais de contratação na década

1 Como esclarece Paulo Lôbo (2011, p. 123), a desigualdade e o desequilíbrio "nas posições contratuais sempre houve na sociedade de economia de mercado. Todavia, as condições gerais dos contratos não apenas resultam de genético desequilíbrio dos poderes negociais, mas assumem caráter geral, abstrato e inalterável por acordo, quando são incorporadas aos contratos individuais". 
de setenta, época em que o tema já vinha sendo debatido na doutrina e na jurisprudência há mais de uma década. Inicialmente, a temática foi tratada em 9 de dezembro de 1976, fora do Código Civil alemão (BGB), no âmbito da "Lei sobre a regulamentação do direito das condições gerais de contratação" (Gesetz zur Regelung des Rechts der Allgemeinen Geschäftsbedingungen - AGBG) (MEDICUS, 2010, p. 162).

Entretanto, desde o ano de 2002 a referida lei (AGBG) foi integrada ao BGB, no livro 2, que trata das obrigações (Recht der Schuldverhältnisse). De fato, com a reforma do direito das obrigações no ano de 2002, que foi feita pela "Lei de modernização do direito das obrigações" (Gesetz zur Modernisierung des Schuldrechts), as disposições de direito material sobre as condições gerais de contratação foram incluídas no BGB ( $\S 305$ a 310)². Para tanto, houve um amplo aproveitamento do texto das regras da AGBG, bem como foram feitas algumas correções na redação da lei anterior (BROX; WALKER, 2019, p. 39-40).

Além disso, as disposições normativas em questão, pelo menos em parte, constituem a transposição da Diretiva 93/13/CEE do Conselho, de 5 de Abril de 1993, relativa às cláusulas abusivas nos contratos celebrados com os consumidores, valendo, na dúvida, a interpretação em conformidade com a referida diretiva (LOOSCHELDERS, 2017, p. 121).

Ademais, é de se notar que os $\S \S 305$ e seguintes do BGB, ao contrário da mencionada diretiva, não se aplicam unicamente às relações contratuais entre consumidores e fornecedores. Compreendem regras precisas sobre a incorporação de condições gerais de contratação, bem como sua interpretação. Muito mais que um simples elemento do direito do consumidor, o direito alemão vê a matéria como regulação da formação do contrato (FROMONT; KNETSCH, 2017, p. 126).

Em todo caso, deve-se ressaltar que o legislador alemão, sob o pretexto de incorporar ao direito interno as diretivas europeias referentes aos contratantes vulneráveis, acabou indo além da proteção mínima exigida pelo direito europeu, bem como ainda promoveu a incorporação da matéria no BGB, retornando ao seio da codificação civil temática que tradicionalmente vinha sendo regrada por microssistemas (LÔBO, 2011, p. 127).

\section{O CONCEITO DE CONDIÇÕES GERAIS DE CONTRATAÇÃO}

No direito alemão, diferentemente do que ocorre no direito brasileiro, existem regras minuciosas, claras e precisas acerca das condições gerais de contratação ${ }^{3}$. O legislador alemão não deu espaço para um modelo jurídico de caráter aberto, como o adotado pelo Código Civil brasileiro, que pretensamente "proporciona ao juiz a possibilidade de encontrar a equidade" (REALE, 1986,

2 O BGB apresenta um sistema de controle bastante complexo das condições gerais de contratação, diferentemente do que ocorreu no Código Civil brasileiro de 2002, que não trata desse fenômeno, salvo em dois artigos (arts. 423 e 424), que cuidam de regras básicas sobre o contrato de adesão, mas confundem conteúdo com continente (LÔBO, 2011, p. 122).

3 O termo condições gerais de contratação já se tornou usual no direito brasileiro. Apesar disso, Rosa Maria de Andrade Nery e Nelson Nery Junior observam, com bastante propriedade, que é mais adequada tecnicamente a utilização do termo cláusulas gerais dos contratos. Esclarecem que condição (Bedingung), nos termos do $\S 158$ do BGB, tem o mesmo significado dado ao vocábulo pelo art. 121 do Código Civil de 2002. Todavia, destacam que se admite a continuidade do uso da "expressão condições gerais dos contratos em face de sua imediata aceitação na doutrina ocidental moderna” (NERY; NERY JUNIOR, 2016, p. 182). 
p. 47).

Nessa linha, o § 305, 1 do BGB define as condições gerais de contratação como todas as cláusulas contratuais pré-redigidas para uma multiplicidade de contratos, que uma das partes (utilizador) impõe à outra no momento da conclusão do contrato (SAKOWSKI, 2014, p. 96).

Para a caracterização como condição geral de contratação, o direito alemão considera irrelevante a maneira como ocorreu a sua fixação, qual o seu alcance, bem como se foi impressa ou simplesmente escrita $^{4}$. Não importa a forma do contrato, isto é, se foi celebrado por escrito ou se foi celebrado informalmente (de forma oral). As condições gerais de contratação, mesmo no caso de contratos formais, não precisam ser incluídas no instrumento contratual, bastando sua exibição em um lugar visível no estabelecimento comercial, como na área dos caixas (BROX; WALKER, 2019, p. 41). Em todo caso, é importante notar que os termos e condições desse tipo de contrato foram formulados antecipadamente (vorformuliert) e apresentados unilateralmente quando da celebração da avença (BÄHR, 2013, p. 121). Isso significa que essas cláusulas não foram particularmente negociadas entre as partes, pois caso contrário, se realmente houve um sério debate entre as partes acerca das cláusulas (KLUNZINGER, 2013, p. 111), não se estará diante de condições gerais de contratação ( $\$ 305,1,3$ do $\mathrm{BGB})^{5}$. E aqui vale observar que não tem relevo o fato de que aquele que impôs a cláusula apenas utilizou um modelo de contrato que foi estabelecido por um terceiro (LOOSCHELDERS, 2017, p. 123). Nesse ponto, fica claro porque a lei empregou o termo utilizador (Verwender) e não a expressão estipulante, que é mais restrita (FROMONT; KNETSCH, 2017, p. 126).

Outrossim, a cláusula deve ter sido redigida para uma multiplicidade de contratos (für eine Vielzahl von Verträgen vorformulierten Vertragsbedingungen), isto é, de maneira geral e impessoal, abstraindo situações contratuais específicas. Com isso, a redação legal alemã buscou colocar fim a um entendimento jurisprudencial do Tribunal Federal de Justiça (Bundesgerichtshof - BGH), que exigia que a cláusula fosse redigida para um número indeterminado de contratos (HIRSCH, 2012, p. 180). Desse modo, a qualificação como condição geral de contratação pode ser aceita mesmo se a cláusula foi redigida para um número preciso de contratos, falando a doutrina em pelo menos três contratos (FÖRSCHLER, 2018, p. 80). Excepcionalmente, no que toca às relações de consumo,

$4 \S 305$ do BGB (Einbeziehung Allgemeiner Geschäftsbedingungen in den Vertrag): (1) Allgemeine Geschäftsbedingungen sind alle für eine Vielzahl von Verträgen vorformulierten Vertragsbedingungen, die eine Vertragspartei (Verwender) der anderen Vertragspartei bei Abschluss eines Vertrags stellt. Gleichgültig ist, ob die Bestimmungen einen äußerlich gesonderten Bestandteil des Vertrags bilden oder in die Vertragsurkunde selbst aufgenommen werden, welchen Umfang sie haben, in welcher Schriftart sie verfasst sind und welche Form der Vertrag hat. Allgemeine Geschäftsbedingungen liegen nicht vor, soweit die Vertragsbedingungen zwischen den Vertragsparteien im Einzelnen ausgehandelt sind. Tradução livre do § 305 do BGB (Incorporação das condições gerais de contratação no contrato): (1) São condições gerais de contratação todas as cláusulas contratuais predispostas para uma pluralidade de contratos, que uma parte contratual (utilizador) apresenta à outra parte contratual na conclusão do contrato. É irrelevante se as cláusulas constituem uma parte independente externa do contrato ou se fazem parte do próprio documento contratual, qual extensão tenham, em que forma escrita estejam redigidas e a forma que tenha o contrato. Não existem condições gerais de contratação no caso em que as cláusulas do contrato tenham sido negociadas individualmente entre as partes contratuais.

5 Conforme já foi decidido pelo Tribunal Federal de Justiça (BGH), somente pode-se falar em verdadeira negociação individual se o utilizador das condições gerais realmente aceita que as disposições possam ser alteradas, com real possiblidade de influenciar na formação do conteúdo das cláusulas contratuais. O simples fato de o parceiro contratual do utilizador poder escolher entre duas variantes, não havendo a possibilidade de apresentar e aplicar, em alternativa, propostas de texto próprias, não é suficiente para que se possa falar na existência de negociação individual (BROX; WALKER, 2019, p. 41). 
admite-se a proteção do consumidor pelas regras das condições gerais de contratação mesmo se existir apenas um contrato (BOECKEN, 2019, p. 180).

Ademais, o $\S 305,1$ do BGB dispõe que é necessária a imposição das cláusulas pelo utilizador ao outro contratante, não existindo então a possibilidade de modificação ou de negociação do conteúdo das cláusulas em questão. Essa exigência tem origem no objetivo inicial do legislador alemão de constituir uma proteção à parte contratual que está impossibilitada de defender seus interesses diante das condições gerais de contratação. Assim sendo, as normas sobre as condições gerais de contratação não se enquadram como regras dispositivas, mas sim como normas cogentes (BROX; WALKER, 2019, p. 41).

Desse modo, vê-se aqui mais uma diferença entre o direito alemão e o direito brasileiro, pois o Código Civil de 2002 não somente não apresentou uma definição das condições gerais de contratação como também não cuidou da matéria de forma tão acurada, preferindo um modelo jurídico aberto. Todavia, como observa Paulo Lôbo (2011, p. 126), a "experiência no mundo inteiro provou o contrário, pois relações jurídicas desiguais, geradoras de conflitos agudos e constantes, exigem regras de jogo claras e específicas", não se mostrando adequada a utilização do modelo jurídico aberto.

Pois bem, apresentada a definição das condições gerais de contratação, passa-se agora à análise do seu complexo sistema de controle, que é composto por três etapas: a) campo de aplicação; b) incorporação no contrato e; c) controle do conteúdo (BOECKEN, 2019, p. 179).

\section{O CAMPO DE APLICAÇÃO DAS CONDIÇÕES GERAIS DE CONTRATAÇÃO}

Com o objetivo de reforçar as soluções jurisprudenciais elaboradas pelo Tribunal Federal de Justiça (BGH) após a Segunda Guerra Mundial, o legislador alemão procurou alargar ao máximo o campo de aplicação das condições gerais de contratação (BOECKEN, 2019, p. 180). Para tanto, parte-se da definição das condições gerais de contratação, que tem seu campo de atuação modificado pelo $\S 310$ do $\mathrm{BGB}$, no qual são reconhecidos um campo de aplicação objetivo (sachlicher Anwendungsbereich) e um campo de aplicação pessoal (persönlicher Anwendungsbereich), que abrangem tanto o cumprimento da obrigação principal como da obrigação acessória (WOLF; NEUNER, 2016, p. 575).

\subsection{Campo de Aplicação Objetivo}

As normas a respeito das condições gerais de contratação, a despeito de se localizarem no âmbito do direito das obrigações (Schuldrecht), têm aplicação, como regra, em todo tipo de contratação de direito privado (WEILER, 2016, p. 125).

Entretanto, conforme estabelece o $\S 310,4$ do BGB, essas disposições não são aplicáveis aos contratos da área de direito de família, sucessões, sociedades (KLUNZINGER, 2013, p. 127), pois nesses casos não há que se falar, em princípio, em superioridade de uma parte em relação 
à outra no que toca à conclusão de tais contratos (BROX; WALKER, 2019, p. 60). Também estão fora do campo de aplicação os contratos de fornecimento de determinados serviços, como eletricidade, gás, água etc. (WOLF; NEUNER, 2016, p. 575-576). Dessa maneira, tais disposições não fazem parte do campo de aplicação objetivo das condições gerais de contratação (sachlicher Anwendungsbereich).

Por outro lado, tais normas valem para os contratos individuais de trabalho, uma vez que os vínculos entre empregador e empregado constituem relações jurídicas obrigacionais (BOECKEN, 2019, p. 181). Em todo caso, o $\S 310,4$, 2 do BGB estipula que, na apreciação das condições gerais de contratação, "as particularidades aplicáveis em matéria de direito do trabalho devem ser levadas em conta de forma adequada" (BÄHR, 2013, p. 120).

\subsection{Campo de Aplicação Pessoal}

Em relação ao campo pessoal (persönlicher Anwendungsbereich), as condições gerais de contratação são aplicáveis aos contratos envolvendo consumidores (contratos celebrados entre um fornecedor e um consumidor).

Com efeito, a obrigação de transpor a Diretiva 93/13/CEE do Conselho, de 5 de Abril de 1993, relativa às cláusulas abusivas nos contratos celebrados com os consumidores, forçou o legislador alemão a rever vários pontos do campo de aplicação da legislação sobre condições gerais de contratação. Nesse contexto, vale notar que o $\S 310,3,1$ do BGB prevê que "as condições gerais de contratação são consideradas como impostas pelo fornecedor, salvo se tiverem sido introduzidas no contrato pelo consumidor".

Aplicam-se ainda aos contratos de consumo algumas disposições específicas, que dizem respeito particularmente ao controle do conteúdo das cláusulas contratuais, que muitas vezes podem ser desvantajosas para o consumidor (BÄHR, 2013, p. 121). Em contrapartida, as regras sobre as condições gerais de contratação excepcionalmente não têm aplicação quando as cláusulas foram introduzidas no contrato pelo próprio consumidor (SAKOWSKI, 2014, p. 97).

Nessa hipótese, pode-se constatar que o critério de aplicação não é o estado de superioridade econômica específico das relações entre fornecedor e consumidor, mas sim a efetiva possibilidade de negociação individual. Aliás, mesmo um contrato estabelecido entre profissionais permite a aplicação da legislação relativa às condições gerais de contratação, desde que o contrato não seja objeto de negociação individual (§ 305 do BGB) (FROMONT; KNETSCH, 2017, p. 126).

Vale ainda notar que na hipótese de utilização das condições gerais de contratação em relação a um empresário (de uma pessoa jurídica de direito público), não se aplicam as disposições relativas à inclusão das condições gerais de contratação (§ 305, 2 e 3) (BOECKEN, 2019, p. 184). Todavia, ocorre o controle do conteúdo por meio da cláusula geral do $§ 307(\S 310,1,2)$, que será analisada adiante (BROX; WALKER, 2019, p. 59). 


\section{A INCORPORAÇÃO DAS CONDIÇÕES GERAIS DE CONTRATAÇÃO}

As condições gerais de contratação não são normas jurídicas (KLUNZINGER, 2013, p. 111). Por isso, para ingressarem na esfera contratual, dependem tanto do consentimento como do conhecimento de seu conteúdo pelas partes contratantes (BRÖMMELMEYER, 2014, p. 67).

A natureza contratual das condições gerais de contratação requer, logicamente, que as partes estejam de acordo com a sua aplicação (§ 305, 2, in fine do BGB). Nesse ponto, a aceitação das condições não difere do consentimento dado em um contrato individualmente negociado. Assim sendo, a aceitação das condições gerais pelas partes resulta do consentimento dado na conclusão do contrato (Konsensualprinzip), que pode ser expresso ou tácito (EISENHARDT, 2018, p. 62).

Conforme o $\S 305,2,1$ do BGB, as partes contratantes devem estar de acordo com o fato das condições gerais de contratação integrarem o que foi pactuado. Se não for feita expressa referência à existência das condições, quando da conclusão do negócio, a lei alemã considera que elas não se tornam parte integrante do contrato (BROX; WALKER, 2019, p. 44).

Além disso, é ainda necessário, como regra, que a parte contratante, de maneira razoável (in zumutbarer Weise), tenha a possibilidade de tomar conhecimento do conteúdo das condições ( 3 305, 2, 2 do BGB), o que inclui as condições disponibilizadas na internet (FÖRSCHLER, 2018, p. 82). É dizer, considera-se tomar conhecimento de forma razoável quando as cláusulas são inteligíveis e acessíveis, o que exige inclusive que se leve em consideração eventuais necessidades especiais dos contratantes, como, por exemplo, a existência de deficiência visual (WOLF; NEUNER, 2016, p. 577). Tal regra pode ser afastada, excepcionalmente, no que toca a determinadas áreas privilegiadas, como em certos serviços de telecomunicações e transporte público, valendo o disposto no $\S 305$ a do BGB (EISENHARDT, 2018, p. 63).

As condições gerais de contratação são particularmente problemáticas quando se desviam das disposições legais em detrimento de uma das partes do contrato, introduzindo condições atípicas, objetivamente não habituais (ungewöhnlich) para o tipo de transação concluída (BRÖMMELMEYER, 2014, p. 68). Normalmente os clientes apenas concordam em se submeterem a elas porque confiam que apenas modificam regras típicas do negócio jurídico, mas não alteram os princípios fundamentais da transação realizada (BÄHR, 2013, p. 122).

A fim de proteger esta confiança na normalidade das condições gerais de contratação, o $\S 305$ c do BGB estipula que as "cláusulas surpresa" (Überraschungsklauseln), ou seja, aquelas com as quais o contratante normalmente não contaria, não fazem parte do contrato (BOECKEN, 2019, p. 185). E nesse sentido o Tribunal Federal de Justiça (BGH) deduz que não são admissíveis em relação ao contratante ordinário as cláusulas que tenham como efeito engano ou fraude (Überrumpelungs- und Übertölpelungseffekt) (FROMONT; KNETSCH, 2017, p. 128).

Para tanto, deve ser aplicado um critério que seja objetivo, isto é, leva-se em conta a capacidade de compreensão de um cliente médio. Assim sendo, as condições gerais de contratação devem ser de fácil leitura para o cliente médio, o que toma em conta o tipo e o tamanho da imagem 
escrita. Igualmente, é necessária a compreensão das cláusulas pelo cliente sem dispêndio excessivo de tempo (BROX; WALKER, 2019, p. 43).

Outrossim, também se utiliza o critério da localização da cláusula para se averiguar se se está diante de uma cláusula surpresa. É dizer: causa surpresa ao contratante a colocação de uma cláusula em local do contrato cuja temática não guarda nenhuma relação com o assunto tratado. Essa situação ocorre, por exemplo, se entre as cláusulas que tratam do prazo de entrega da mercadoria é acrescentada uma cláusula de exclusão da responsabilidade do fornecedor, ficando evidente o contexto totalmente diverso de sua colocação (BOECKEN, 2019, p. 185-186).

Em todo caso, vale notar que a inclusão das condições gerais de contratação não constitui um negócio jurídico particular, mas tão somente uma parte do próprio contrato.

\section{INTERPRETAÇÃO DAS CONDIÇÕES GERAIS DE CONTRATAÇÃO E PREVALÊNCIA DOS ACORDOS INDIVIDUAIS}

$\mathrm{Na}$ interpretação das condições gerais de contratação, não havendo disposição em sentido contrário, aplicam-se as regras gerais do BGB, que tratam da interpretação $(\S \S 133,157)$ e da eficácia $(\S \S 134,138)$ da declaração de vontade (BROX; WALKER, 2019, p. 43). Ao lado da utilização da interpretação comum dos contratos, também se exige uma interpretação típica das condições gerais de contratação (LÔBO, 2011, p. 123).

Nessa senda, eventualmente são celebrados acordos individuais adicionais com o cliente, os quais contradizem as condições gerais de contratação que foram simultaneamente acordadas. Assim sendo, aplica-se o $\S 305$ b do BGB, o qual determina que são ineficazes as cláusulas que estiverem em contradição direta ou indireta com o que foi pactuado expressamente e de forma individual pelas partes (Vorrang der Individualabrede) (BÄHR, 2013, p. 122).

$\mathrm{O} \S 305 \mathrm{~b}$ do BGB é uma regra de colisão (Kollisionsregel), que dá prevalência aos acordos individuais em detrimento das condições gerais de contratação (FÖRSCHLER, 2018, p. 82). Essa regra se fundamenta na maior consideração dada pelo BGB aos acordos individuais que às disposições abstratas previamente formuladas por apenas uma das partes, o que representa evidente consagração do princípio da autonomia privada (BRÖMMELMEYER, 2014, p. 68).

$\mathrm{Na}$ ausência de incorporação, seja total ou parcial, das condições gerais, o contrato permanece eficaz em virtude do $§ 306$ do BGB (der Vertrag im Übrigen wirksam). Tal dispositivo, em sua alínea 2, dispõe que "o conteúdo do contrato se regula conforme as disposições legais" (FROMONT; KNETSCH, 2017, p. 130-134). Na falta de regras supletivas adequadas, o juiz deverá preencher as lacunas do contrato por meio de interpretação completiva (ergänzende Vetragsauslegung), levando em conta os interesses das partes (BOECKEN, 2019, p. 189-190).

Excepcionalmente, o contrato será integralmente ineficaz, "se a sua manutenção, tendo em conta a alteração prevista na alínea 2, representar um rigor excepcional para uma das partes" ( $§ 306,3$ do BGB) (SAKOWSKI, 2014, p. 101). Nessa situação, não se pode simplesmente retirar a cláusula do contrato, visto que a manutenção do acordado sem referida cláusula levaria ao desequilíbrio de 
sua equação financeira (Störung des Vertragsgleichgewichts). Semelhante solução será aplicada quando ocorrer a incorporação das condições gerais, mas seu conteúdo for declarado ineficaz (BROX; WALKER, 2019, p. 56).

Por fim, vale lembrar que a interpretação das condições gerais de contratação, diferentemente do que ocorre com as regras gerais do BGB, não parte da situação concreta do contratante, mas considera um contratante médio (homo medius), o que se extrai quando se pensa em uma multiplicidade de negócios jurídicos (BROX; WALKER, 2019, p. 46).

\section{O CONTROLE DO CONTEÚDO DAS CONDIÇÕES GERAIS DE CONTRATAÇÃO}

Superada a fase de incorporação das condições gerais de contratação, passa-se à fase de controle do seu conteúdo (Inhaltskontrolle). Nos $\S \S 307$ a 309 do BGB são estabelecidos os requisitos para que as condições gerais de contratação, que foram efetivamente incluídas no contrato, possam ser consideradas eficazes (FÖRSCHLER, 2018, p. 83).

O controle de conteúdo segue a ordem inversa dos $\S \S 307$ a 309 do BGB. Isso significa que primeiro são analisadas as regras do $\S 309$, que proíbem determinadas cláusulas sem necessidade de valoração. Em seguida, passa-se à análise do $\S 308$, cujas cláusulas proibidas necessitam de valoração de conteúdo (WOLF; NEUNER, 2016, p. 583). Por fim, caso não tenha sido violada nenhuma proibição dos $\S \S 309$ e 308, leva-se em conta a boa-fé objetiva (Treu und Glauben), como está estabelecido na cláusula geral do $§ 307$ do BGB (BOECKEN, 2019, p. 186-188).

Desse modo, considerando a sequência determinada pela legislação alemã no que toca ao controle das cláusulas, serão primeiro analisados os $\S \S 308$ e 309 (Klauselverbote). Em seguida, estudarse-á a cláusula geral (Generalklausel) do § 307 do BGB (SAKOWSKI, 2014, p. 97).

\subsection{As Listas Previstas nos $§ § 308$ E 309 do BGB}

Os $\S \S 308$ e 309 do BGB contêm duas listas que enumeram diferentes categorias de cláusulas que o legislador presume abusivas. Essas listas não são aplicáveis aos contratos entre profissionais, visto que seu campo de aplicação se limita aos contratos celebrados entre particulares e aos contratos de consumo (FROMONT; KNETSCH, 2017, p. 133).

A primeira lista contém as cláusulas em que o juiz tem a possibilidade de constatar a ineficácia, dispondo de um poder de apreciação (Klauselverbote mit Wertungsmöglichkeit) (RÜTHERS; STADLER, 2011, p. 252), o que justifica a utilização da expressão "lista cinza". A segunda lista enumera os tipos de cláusulas cuja ineficácia deve ser declarada pelo juiz (Klauselverbote ohne Wertungsmöglichkeit), ou seja, nesse caso a lei não reconhece nenhuma margem de manobra, daí o nome "lista negra" (NERY; NERY JUNIOR, 2016, p. 185).

\section{A) A "LISTA CINZA"}


A "lista cinza" do $\S 308$ do BGB enumera tipos de cláusulas que são vedadas se forem inapropriadas, não razoáveis ou objetivamente injustificadas. Como o juiz pode apreciar a eficácia dessas cláusulas, a legislação apresenta normas que contêm conceitos jurídicos indeterminados (unbestimmte Rechtsbegriffe), o que permite a sua valoração em cada caso concreto (BRÖMMELMEYER, 2014, p. 72).

Tais cláusulas suspeitas podem ser reagrupadas em quatro categorias. A primeira categoria compreende as cláusulas relativas a prazos de aceitação, de pagamento, de verificação e de execução, que não devem ser nem excessivamente longos e nem insuficientemente determinados. A segunda categoria compreende as cláusulas que autorizam a resolução do contrato ou a modificação da prestação sem um motivo preciso. O terceiro grupo engloba as cláusulas que dão a um comportamento determinado do cocontratante o sentido de uma declaração de vontade ou que instituem uma presunção de recepção por uma declaração do utilizador. Por fim, o quarto grupo é constituído de cláusulas que preveem que em caso de resolução ou resilição o cocontratante deverá pagar ao estipulante somas exageradamente elevadas (FROMONT; KNETSCH, 2017, p. 132).

\section{B) A "LISTA NEGRA"}

A "lista negra" do $§ 309$ do BGB enumera as cláusulas que são vedadas. O legislador presume, irrefragavelmente, que essas cláusulas sempre prejudicam, de forma desproporcional, a outra parte (BOECKEN, 2019, p. 188). Não existe a possibilidade de uma ponderação de interesses, ficando o juiz obrigado a declará-las ineficazes (Klauselverbote ohne Wertungsmöglichkeit) (BROX; WALKER, 2019, p. 48).

Tais cláusulas são definidas de forma precisa, são bastante numerosas e mereceriam uma análise mais pormenorizada, mesmo porque cada uma delas constitui objeto de julgados importantes dos tribunais alemães. Sem exaurir a temática, podem ser citadas as cláusulas relativas ao aumento do preço após a conclusão do contrato, as que estabelecem um direito de recusa de execução da prestação, as que proíbem a compensação da dívida com créditos mútuos, as que fixam prazos adicionais, as cláusulas penais, as cláusulas de exoneração ou limitação de responsabilidade em caso de culpa grave, bem como as cláusulas que alterem a repartição do ônus da prova em detrimento do cocontratante (WOLF; NEUNER, 2016, p. 583).

Por conseguinte, no que toca ao controle do conteúdo das condições gerais de contratação, deve-se inicialmente examinar a presença de cláusulas que integrariam a lista do $\S 309$. Em seguida, não havendo enquadramento no $\S 309$, passa-se à verificação da existência de cláusulas que possam ser subsumidas no $\S 308$. Por fim, analisa-se se há alguma disposição contratual que violou o $\S 307$, regra que apresenta uma cláusula geral de controle do conteúdo (Generalklausel der Inhaltskontrolle) (BROX; WALKER, 2019, p. 48).

\subsection{A Cláusula Geral de Controle de Conteúdo Prevista no § 307 do BGB}


A partir da integração das disposições da Lei de 9 de dezembro de 1976 no BGB, o legislador consagrou o controle das condições gerais de contratação, que a jurisprudência, em um primeiro momento, tinha elaborado com base no critério da desvantagem injustificada.

Desta feita, o principal objetivo das normas em matéria de defesa da parte que se subordina às condições gerais de contratação é a verificação do conteúdo das cláusulas, isto é, se o utilizador das cláusulas não está impondo regras que prejudiquem injustamente a outra parte.

\section{A) DESVANTAGEM INJUSTIFICADA}

O § 307, I do BGB apresenta uma cláusula geral de controle de conteúdo (Generalklausel der Inhaltskontrolle), estabelecendo que as condições gerais de contratação são ineficazes, quando, contrariando exigências da boa-fé objetiva (Treu und Glauben - § 242 do BGB), prejudicam injustificadamente o parceiro contratual do utilizador (SAKOWSKI, 2014, p. 100).

Para apreciar se a cláusula litigiosa criou efetivamente uma desvantagem injustificada (unangemessene Benachteiligung), o juiz deverá determinar os interesses em jogo das partes contratantes, sopesando a situação com a manutenção da cláusula e com a sua supressão (WOLF; NEUNER, 2016, p. 586). De forma mais ampla, trata-se de investigar se o utilizador tentou perseguir, ao recorrer às cláusulas padronizadas, exclusivamente seus próprios interesses, sem levar em conta a situação do cocontratante (FROMONT; KNETSCH, 2017, p. 131).

\section{B) REGRA DA TRANSPARÊNCIA}

Entre as cláusulas que prejudicam injustificadamente o cocontratante estão aquelas pouco claras e/ou não compreensíveis, que podem violar a regra da transparência (Transparenzgebot) das condições gerais de contratação (BOECKEN, 2019, p. 189). O dever de transparência está codificado no $\S 307,1$, 2 do BGB, o qual dispõe que a falta de clareza e de inteligibilidade da cláusula pode constituir uma desvantagem injustificável (KLUNZINGER, 2013, p. 118). Isso decorre do fato de que os direitos e deveres dos contratantes devem ser formulados em cláusulas contratuais que sejam apresentadas de forma clara, certa, determinada e compreensível (BROX; WALKER, 2019, p. 54). Assim sendo, uma cláusula que não preencha esses requisitos e que conduza a uma desvantagem injustificada para o parceiro contratual pode ser considerada globalmente ineficaz (BÄHR, 2013, p. 122).

Outrossim, como o utilizador estabelece unilateralmente as condições gerais, é ele que deve se preocupar com problemas relacionados à sua clareza. É dever do utilizador formular as cláusulas de maneira a evitar dificuldades em sua compreensão. Eventuais dúvidas sobre a interpretação das condições gerais são ônus do seu utilizador, de forma que se uma cláusula permite várias interpretações possíveis, deve-se aplicar a interpretação mais favorável ao cliente (SAKOWSKI, 2014, p. 100). 


\section{C) CASOS DE APLICAÇÃO DA DESVANTAGEM INJUSTIFICADA}

Conforme o $\S 307,2$ do BGB, em caso de dúvida, presume-se a desvantagem injustificada quando uma disposição: a) não é compatível com as ideias fundamentais da regulação legal que ela derrogou (Abweichung von wesentlichen Grundgedanken); b) quando ela restringe direitos e obrigações essenciais decorrentes da natureza do contrato, de tal forma que compromete a realização do objetivo do contrato (Einschränkung wesentlicher Rechte und Pflichten). Assim sendo, pelo texto do $\S 307,2$ do BGB, procura o legislador concretizar o critério geral da desvantagem injustificada, apresentando dois casos de aplicação (gesetzliche Regelbeispiele) (KLUNZINGER, 2013, p. 117).

Desse modo, a primeira disposição foca a incompatibilidade de uma cláusula padrão com o modelo das regras de um tipo contratual determinado. A segunda regra, por seu turno, trata das cláusulas que comprometem a realização do objetivo contratual (Vertragszweck) (RÜTHERS; STADLER, 2011, p. 253), o que pode ser o caso das cláusulas exoneratórias ou limitadoras de responsabilidade, notadamente quando elas se aplicam ao descumprimento de uma obrigação fundamental do contrato (FROMONT; KNETSCH, 2017, p. 132).

A revisão de conteúdo das condições gerais de contratação leva em conta que é possível a negociação em torno de normas de caráter dispositivo, que podem ser afastadas, alteradas ou complementadas ( $§ 307,3,1$ do BGB) (MEDICUS, 2010, p. 176). Não se permite, por outro lado, negociações envolvendo normas cogentes, de forma que qualquer cláusula que afaste direito cogente será considerada inválida (BÄHR, 2013, p. 123). Em todo caso, não se subordinam ao controle as cláusulas que simplesmente repetem o conteúdo da lei, as quais são chamadas de cláusulas declaratórias (deklaratorische Klauseln) (BOECKEN, 2019, p. 187).

Com efeito, a desvantagem injustificada que conduz à invalidade das condições gerais de contratação decorre do seu grau de desvio em relação à regulamentação legal normal. Todavia, para a aplicação dessa disposição, é necessária a existência de regulação detalhada pela legislação da relação contratual (BÄHR, 2013, p. 123).

Por fim, de acordo com o $\S 307,3$ do BGB, o controle de conteúdo se aplica às disposições que derroguem regras supletivas ou as complementem, mas ficam de fora as cláusulas relativas ao preço e à prestação, que são objeto do contrato. Evita-se, com isso, que o juiz tenha que se pronunciar sobre o equilíbrio entre as prestações ou que ele possa modificar, pela via do controle das condições gerais de contratação, o conteúdo da lei (FROMONT; KNETSCH, 2017, p. 130).

\section{O RECONHECIMENTO JUDICIAL DA INEFICÁCIA DAS CONDIÇÕES GERAIS}

Os contratantes podem invocar, em um litígio judicial individual, a ineficácia das condições gerais de contração (Individualrechtsschutz) (BRÖMMELMEYER, 2014, p. 74). Tal discussão judicial pode envolver a utilização de direito próprio do contratante contra as cláusulas contratuais 
ou também pode constituir meio de defesa (SAKOWSKI, 2014, p. 101).

Por outro lado, como as condições gerais de contratação frequentemente atingem os consumidores, a "Lei relativa às ações inibitórias em matéria de direitos dos consumidores e outras infrações" (Gesetz über Unterlassungsklagen bei Verbraucherrechts- und anderen Verstößen - UKlaG) concede a determinadas associações o direito de questionar judicialmente, via ação coletiva, a eficácia dessas condições gerais de contratação, proibindo-se a sua utilização futura (RÜTHERS; STADLER, 2011, p. 258-259).

Tal espécie de ação coletiva (Verbandsklage) pode ser ajuizada por associações de defesa do consumidor (Verbraucherschutzverbände), bem como por associações de promoção de interesses da indústria e do comércio (Wirtschftsverbände) (BOECKEN, 2019, p. 179). A proteção coletiva contra condições gerais de contratação não depende da existência de um caso concreto (WOLF; NEUNER, 2016, p. 581), ponto que aproxima a tutela coletiva alemã do controle preventivo judicial brasileiro, feito principalmente pela via da ação civil pública (LÔBO, 2011, p. 131).

No que diz respeito ao processamento dessa ação coletiva (Verbandsklage), valem as regras gerais do Código de Processo Civil (Zivilprozessordnung - ZPO), ressalvadas regras especiais da UKlaG (BROX; WALKER, 2019, p. 58).

\section{CONCLUSÃO}

O direito alemão apresenta um sistema de controle das cláusulas gerais de contratação bastante elaborado. Tal sistema, ao definir as condições gerais de contratação, apresenta os pressupostos necessários para que um contrato possa ser submetido às regras dos $\S \S 305$ a 310 do BGB. A definição e delimitação do campo de atuação das condições gerais de contratação pelo legislador alemão certamente facilita muito o trabalho do operador do direito. O mesmo infelizmente não ocorre no Código Civil de 2002, haja vista a ausência de previsão legal específica sobre o assunto.

No sistema alemão a proteção da parte hipossuficiente é garantida, inicialmente, pelo controle de introdução das cláusulas, o qual exige que a parte contratante tenha conhecimento da existência das condições gerais de contratação, tenha acesso a elas, bem como esteja de acordo, proibindo-se cláusulas surpresa. As regras de interpretação também são bastante consistentes, pois, em caso de dúvida, levam à interpretação em desfavor do utilizador das cláusulas e ainda dão prevalência ao que foi contratado por meio de negociação individual. Ademais, o controle de conteúdo é bastante detalhado, partindo de cláusulas que sempre são proibidas, passando por cláusulas que podem ser ou não afastadas pelo juiz e prevendo, ainda, uma cláusula geral de controle de conteúdo, que permite ao juiz resolver casos não abrangidos pelas regras anteriores.

Facilmente pode-se notar que há uma oposição entre a apreciação in concreto do direito brasileiro e a apreciação in abstracto do direito alemão, o que se extrai do campo de aplicação dos dispositivos legais. Realmente, ao conceder ao juiz o poder de apreciar o caráter abusivo de uma cláusula contratual, o legislador brasileiro optou por uma apreciação in concreto, o que pode 
prejudicar a segurança jurídica. O direito alemão buscou a solução inversa, pois o controle judicial das condições gerais é realizado, como regra, abstraindo-se considerações relacionadas ao lugar, à qualidade pessoal das partes contratantes, o contexto de formação de contrato e as relações de força.

Todavia, é de se notar que a diretiva 93/13 obrigou o legislador alemão a prever a obrigação do juiz levar em conta as circunstâncias que envolvem a conclusão do contrato quando da apreciação da desvantagem injustificada. Isso incorporou certa dose de apreciação in concreto, o que gerou uma parcial ruptura no sistema alemão, que se fundava apenas na lógica objetiva, passando a expressar uma lógica mista, ou seja: objetiva e subjetiva. Mesmo assim, o modelo proposto pelo legislador europeu considerou que os sistemas abertos são insuficientes para o estabelecimento de controle razoável das condições gerais de contratação, entendimento que certamente se contrapõe ao sistema aberto brasileiro.

No direito brasileiro, por outro lado, somente com o Código de Defesa do Consumidor é que as condições gerais dos contratos foram implicitamente disciplinadas, mas ficaram restritas ao âmbito de abrangência do consumidor. Foram contempladas, sem menção expressa, no Capítulo VI do Código de Defesa do Consumidor, denominado "Da proteção contratual", atinente ao contrato de adesão e às cláusulas abusivas. O Código Civil de 2002, por sua vez, foi bastante econômico ao cuidar da matéria, reservando apenas dois artigos (arts. 423 e 424) ao tratamento do contrato de adesão, que foram colocados nas disposições gerais aplicáveis aos contratos. Nesse contexto, preceitua o art. 423 que se no contrato de adesão houver cláusulas ambíguas ou contraditórias, dever-se-á adotar a interpretação mais favorável ao aderente' ${ }^{6}$. Já o art. 424, por seu turno, evidenciou que são nulas, nos contratos de adesão, as cláusulas que estipulem a renúncia antecipada do aderente a direito resultante da natureza do negócio. Esses artigos estabelecem regras básicas sobre o contrato de adesão, que não são suficientes para abranger as complexas dimensões das condições gerais dos contratos.

Por conseguinte, é patente a insuficiência da legislação brasileira sobre o tema, visto que o Código Civil de 2002 não trata diretamente das condições gerais de contratação, enquanto no Código de Defesa do Consumidor a disciplina é parcial e de determinados pontos do assunto (e.g. cláusulas abusivas), mas seu campo de abrangência é restrito ao consumidor. Assim sendo, diante da importância e da complexidade da matéria, da necessidade de se controlar e inibir abusos, bem como considerando a experiência alemã estudada, que introduziu a temática no BGB e a tratou com considerável minúcia, é premente a revisão do direito positivo brasileiro. Faz-se mister o tratamento de forma mais ampla e acurada das condições gerais de contratação no Brasil, valendo o modelo alemão como um bom paradigma para uma futura reforma do Código Civil de 2002.

\section{REFERÊNCIAS}

BÄHR, Peter. Grundzüge des Bürgerlichen Rechts. 12. ed. München: Franz Vahlen, 2013.

6 Art. 423 do Código Civil. "Quando houver no contrato de adesão cláusulas ambíguas ou contraditórias, dever-se-á adotar a interpretação mais favorável ao aderente". 
BOECKEN, Winfried. BGB: Allgemeiner Teil. 3. ed. Stuttgart: Kohlhammer, 2019.

BRÖMMELMEYER, Christoph. Schuldrecht Allgemeiner Teil. München: C.H. Beck, 2014. BROX, Hans; WALKER, Wolf-Dietrich. Allgemeines Schuldrecht. 49. ed. München: C.H. Beck, 2019.

EISENHARDT, Ulrich. Einführung in das Bürgerliche Recht. 7. ed. Viena: Facultas, 2018. FÖRSCHLER, Peter. Grundzüge des Wirtschaftsprivatrechts. München: Franz Vahlen, 2018. FROMONT, Michel; KNETSCH, Jonas. Droit privé allemand. 2. ed. Paris: LGDJ, 2017. FÜHRICH, Ernst. Wirtschaftsprivatrecht. 12. ed. München: Franz Vahlen, 2014. HIRSCH, Christoph. BGB Allgemeiner Teil. 7. ed. Baden-Baden: Nomos, 2012.

KLUNZINGER, Eugen. Einführung in das Bürgerliche Recht. 16. ed. München: Franz Vahlen, 2013.

LÔBO, Paulo. Direito civil: contratos. São Paulo: Saraiva, 2011.

LOOSCHELDERS, Dirk. Schuldrecht: Allgemeiner Teil. 15. ed. München: Franz Vahlen, 2017. MEDICUS, Dieter. Allgemeiner Teil des BGB. Heidelberg: C.F. Müller, 2010.

NERY, Rosa Maria de Andrade; NERY JUNIOR, Nelson. Instituições de direito civil: contratos. São Paulo: Revista dos Tribunais, 2016. v. 3.

REALE, Miguel. O projeto do Código Civil. São Paulo: Saraiva, 1986.

RÜTHERS, Bernd; STADLER, Astrid. Allgemeiner Teil des BGB. 17. ed. München: C.H. Beck, 2011.

SAKOWSKI, Klaus. Grundlagen des Bürgerlichen Rechts: Eine Einführung für Wirtschaftswissenschaftler. 3. ed. Heidelberg: Springer, 2014.

SCHLECHTRIEM, Peter. Schuldrecht Allgemeiner Teil. 5. ed. Tübingen: Mohr Siebeck, 2003. WEILER, Frank. Schuldrecht Allgemeiner Teil. 3. ed. Baden-Baden: Nomos, 2016.

WOLF, Manfred; NEUNER, Jörg. Allgemeiner Teil des Bürgerlichen Rechts. 11. ed. München: C.H. Beck, 2016.

ZANINI, Leonardo Estevam de Assis. Contratação na sociedade massificada. Revista Brasileira de Direito Civil, Belo Horizonte, v. 14, p. 75-98, out./dez. 2017.

Como citar: ZANINI, Leonardo Estevam de Assis. A contratação na sociedade massificada e as condições gerais de contratação no direito alemão. Scientia Iuris, Londrina, v. 24, n. 2, p. 117 133, jul. 2020. DOI: 0.5433/2178-8189.2020v24p117. ISSN: 2178-8189. 
Recebido em: 25/04/2020.

Aprovado em: 25/06/2020. 